\title{
Influence of internal phase properties on zeta-potential and dielectric constant of $o / w$ emulsion
}

\author{
DEVRAJ RAMBHAU ${ }^{\dagger}$, A K DORLE and B RAMI REDDY \\ Department of Pharmaceutical Sciences, Nagpur University Campus, Amaravati Road, \\ Nagpur 440010 , India \\ ${ }^{\dagger}$ Present address: University College of Pharmaceutical Sciences, Kakaliya University, \\ Warangal 506009 , India
}

\begin{abstract}
Dielectric constant (DEC) of internal phuse influenced the zela potential (ZP) of o/w emulsion prepared with or without emulgent. In both systems ZP and DEC of internal phase exhibited an approximately linear relationship. Using homologous aliphatic hydrocarbons as internal phases, emulsions were prepared with polysorbate-80. Increase in carbon chain length bruught about increase in interfacial area and decrease in ZPs of emulsions. A fair inverse correlation between ZP and DFC of internal phese was reveuled in this series. Increase in phase volume ratio from 0.05 to 0.3 brought about himited chunges in ZPS whereas by lurther increasing phese volume ratio, ZP decrcased stedily. Studies pertaining to the effect of phase volume ratio on $\mathrm{DEC}$ of $\mathrm{o} / \mathrm{w}$ enulsions are in accordance with earlier observations. Increase in phase volume ratio causes a steady decrease in DEC of emulsion. Of the five equations employed, the Bruggeman equation appcars to predict the observed values more accurately.
\end{abstract}

Keywords. Dielectric constant; oil-in-water emulsions; zeta potentials; emulsion rtability.

\section{Introduction}

Most of the earlier work in the field of dielectric properties of emulsions dealt with deriving equations for predicting the DECs of emulsions (Rayleigh 1892; Weiner 1912; Bruggeman 1935; Bottcher 1952; Kubo and Nakamura 1953; Hanai 1968). These equations were based on an erroneous assumption that the dielectric constant (DEC) of an emulsion is a function of dielectric constants and concentrations of twocomponent phases. The presence of emulgent at globule surface constitutes a double layer and confers a certain electric charge. The influcnce of polarization of electrical double layer on the DEC of emulsions was extensively studied earliet in w/o emulsions under changing phase volume ratios (Fradkina 1950; Hanai 1959, 1960, 1961). However studies on o/w emulsions are scanty (Hanai 1962).

Although theoretical postulations reveal that internal phase polarity can influence DEC of emulsions, studies of varying internal phase while keeping its concentration constant, are not available. In emulsions, with a change in internal phase polarity, constitution and charge density of electrical double layer around globules are likely to be affected. It would therefore be worthwhile determining the effect of the properties of internal phase on dielectric constant and diffuse double-layer potential (ZP) in o/w emulsions. The variables pertaining to internal phase considered for this study were: polarity, carbon-chain length and concentration of internal phase. 


\section{Experimental}

Inlernal phases, and their concentrations; emulsitier and its concentration; and conditions of emulsification for various studies are shown in table 1. Purity of the liquids employed as internal phases was ascertained by determining reiractive index and weight per $\mathrm{ml}$.

\subsection{Preparation of enulsions containing polysorbate-80}

In all experiments internal phase was added to the solution of polysorhate-80 and the mixture agitated for a required time continuously in a mixer at $15537 \mathrm{rpm}$. Emulsions thus formed were subjected to various measurements.

\subsection{Preparation of emulsions without emulsifier}

In anticipation of the delicate stability of these emmlsions, they were homogenized by passing them five times through an ultrasonic lomogenizer, after primaty agitation.

Table 1. Materials and method of preparation of emulsions for various studies.

\begin{tabular}{|c|c|c|c|c|}
\hline Study & Intefnal phases & $\begin{array}{l}\text { Phase } \\
\text { volume } \\
\text { ratio }\end{array}$ & $\begin{array}{l}\text { Emulgent per } 100 \mathrm{ml} \\
\text { of emulsion }\end{array}$ & $\begin{array}{l}\text { Mixing lime } \\
\text { in minutes }\end{array}$ \\
\hline I & As listed in table 3 & 0.33 & Wo emulgent was ușed & 5 \\
\hline II & $\begin{array}{l}n-H c x a n e^{\prime} \text { or } \\
n-H e x \rightarrow n l^{\prime} \text { or } n \text {-Hexane containing. } \\
1 \text { or } 10^{\alpha} \% \mathrm{~V} / \mathrm{V} \text {-Hexanol }\end{array}$ & $0 \cdot 33$ & No emulgent was used & 5 \\
\hline III & As listed in table 3 & 0.33 & Polysorbate-80 $1 \mathrm{~g}$ & 3 \\
\hline$I V$ & $\begin{array}{l}n \text {-Hexane or } m \text {-Heptane }{ }^{2} \text { or } \\
n \text {-Octane or } n \text {-Decanc } c^{1} \text { or } \\
n \text {, Tetradecanc }\end{array}$ & 0.10 & Polysorbate- $801 \mathrm{~g}$ & 3 \\
\hline v & Liquid paraffir ${ }^{4}$ & $\begin{array}{l}0.05 \\
0.10 \\
0.15 \\
0.30 \\
0.45 \\
0.60 \\
0.75\end{array}$ & Polysorbale-80 $1 \mathrm{~g}$ & 3 \\
\hline
\end{tabular}

Study I: Effect of DEC of internal phase on ZP of o/w exulsions prepared without using any emulsifier Stady II: ZP changes in hexane-in-watcr enulsions (preparcd without emulsifier) duc to the contanination or n-hexamol in its interna! phasc; Study [Cl: Eltcet of DEC of internal phase on ZP and DEC of OAw enulsions prepared using polysorbale-80; Study IV: Effect of carbon chain length of internal phase on $Z P$ and DEC of o/w entsisions prepared using polysorbate-80; Study V: Effect of phase volume ratio on $7 P$ and DEC of otw emulsion prepared using polysotbatc-80.

1. British Drug House, India; 2. Sisco Chernicals, Lndia; 3. Sigma Chemical Conany, St. Louis MO, USA;

4. Deepti Pharmaceuticals, Nagptur, Indja. 


\subsection{Measurement of DEC and conductivity}

Dielectric constants of the internal phases and conductivities of all the emulsions prepared with polysorbate-80 were measured on a dielectrometer (Universal dielectrometer, type 04-301, Redelkis, Hungary, which operates at a lone frequency of 3 $\mathrm{Mc} / \mathrm{sec}$.

An attempt was made to measure the DECs of emulsions without emulsifier but it majority of them started separating in the dielectrometer cell itself resulting in fluctuation in the readings. As the measurement of DEC of these emulsions was not possible, the following equations were employed to compute their theoretical values.

Rayleigh equation

$$
\varepsilon=\varepsilon_{m}\left[1+\frac{3 \phi}{\frac{\varepsilon_{p}+2 \varepsilon_{m}}{\varepsilon_{p}-\varepsilon_{m}}-\phi-1 \cdot 65 \frac{\varepsilon_{p}-\varepsilon_{m}}{\varepsilon_{p}+\frac{4}{3} \varepsilon_{m}} \cdot \phi^{10 / 3}}\right] .
$$

Wiener equation

$$
\frac{\varepsilon-\varepsilon_{m}}{i+2 \varepsilon_{m}}=\frac{\varepsilon_{p}-\varepsilon_{m}}{\varepsilon_{p}+2 \varepsilon_{m}} \cdot \phi .
$$

Bruggeman equation

$$
\frac{\varepsilon-\varepsilon_{p}}{\varepsilon_{\mathrm{m}}-\varepsilon_{p}}\left(\varepsilon_{m} / \varepsilon\right)^{1 / 3}=1-\phi .
$$

Bottcher equation

$$
\frac{\varepsilon-\varepsilon_{m}}{3 \varepsilon}=\frac{\varepsilon_{p}-\varepsilon_{m}}{\varepsilon_{p}+2 \varepsilon} \cdot \phi
$$

Hanai equation

$$
\frac{2 \varepsilon_{1}-3 \varepsilon_{p}}{2 \varepsilon_{m}-3 \varepsilon_{p}}(1-\phi)^{3 / 2}
$$

where $\varepsilon$ or $\varepsilon_{1}$ is the DEC of emulsion, $\varepsilon_{p}$, the DEC of internal phase, $\varepsilon_{m}$, the DEC of dispersion medium (water) and $\phi$, the phase volume ratio.

\section{Measurement of zeta potential (ZP)}

A cylindrically bored microelcctrophoresis cell equipped with platinum-iridiun electrodes was used to measure the electrophoretic mobility (EM) of diluted emuisions. Emulsions were always diluted to 1 in 200 , except in study $v$ where 1 in 500 dilution was used. Dilution was usuaily performed with distilled water or distilled water saturated with internal phase. The latter procedure was adopted from Elworthy and Florence (1969) who suggested this method to give meaningful mobility values for emulsions containing internal phases which are partially miscible with water.

Potential drop in the cell was measured by a digital voltmeter. The current strength was kept constant during measurements. All mobility measurements were at zero electro-endosmotic flow (Schott and Young 1972). By frequently changing polarity, 
Fifty globules were measured for their mobility. $2 \mathrm{P}$ was calculated from the average mobility value (Smoluchowsky 1918$)$ using $\mathrm{ZP}=(4 \pi n t u) /(\varepsilon E)\left(9 \times 10^{3}\right)$. $\mathrm{ZP}$ is in $\mathrm{mV}$, $n$ is the viscosity of dispersion medium (water) in poise, $u$ the migration velocity (cm/s), $E$ the potential gradient voltage applied/distance between electrodes and $\varepsilon$ the DEC of dispersion medium.

\subsection{Globule size onalysis and computation of interfacial area (IA)}

Size analysis of the globules of emulsion prepared with polysorbate- 80 was performed microscopically. One ml of emulsion was diluted to $25 \mathrm{ml}$ with distilled water. A drop of this was mounted with a drop of glycerine water mixture $(1: 3)$ on a glass slide. Diameters of 500 giobules were measured by viewing the slide under microscope equipped with a standardized eyepiece micrometer. From this data, the IA per ml of emulsion was computed. Size analysis of the emulsions without emulsifier could not be pertormed as a majority of them rapidly coagulated during measurements.

\subsection{Astessment of stability of emulsions}

Based on the shelf-jife of emulsion, a scoring test was devised to make a quick appraisal of the stability where perceptible phase separation was considered as a breaking point. The test was as follows: An emulsion having a shelf-life below 15 min will be difficult to test for its ZP and other parameters of stability, it would therefore be logical to assign a score value of zero to the emulsion, breaking at or below 15 min. The highest scorc value of five was assigned to an emulsion, which was stable for a month or more. Using these boundary score values, a straight line was plotted between the score and shelf-life on a semi-logarithmic paper. From this line the score values for shelf-lives falling between the two boundary values were obtained (table 2).

Table 2. Assessment of emulsion stability based on score values.

Shelf-life
$\begin{aligned} & \text { Emulsification not possibie or breaking at or bejow } \\ & 15 \text { minules }\end{aligned}$




\section{Results and discussion}

\subsection{Effect of properties of internal phase on $Z P$ of o/w emulsion}

Of the thirty seven internal phases (tabie 3) tried, only 25 could form emulsions without emulgents with sufficient stability (stability score 1 or more) to ailow measurements.

Effect of DEC of internal phase on ZP of emulsion formed without emulsifier is illustrated in figure 1 . An approxinately linear relationship appears to exist between $\mathrm{DEC}$ of internal phase and $\mathrm{ZP}(r=0.7655 ; n=23$, at $p<0-01)$. Increase in $\mathrm{ZP}$ with increase in DEC of internal phase may be attributed to the increasing polar nature of internal phase. With increase in polarity of internal phase, an increase in the extent of dipole-dipole interactions between globules of internal phases and dipoles from bulk medium is expected (Mackor 1951; Bockris et al 1963; Bijsterbosch and Lyklema 1964; Ottewill 1962), bringing about changes in $\chi$-potentials. Mackor (1951) reported a shift in zero-point charge of an emulsion with change in $\chi$-potential. He felt that changes in $\chi$-potential reflect a change in the dipolar interaction at interphases.

Figure 1 shows deviations of some of the points from the regression line, p-cresol and methyl salicylate showing deviations to a considerable extent. For a decrease of D.9 unjis of internaj phase $\mathrm{DEC}$ (i.e. $p$-cresol $\mathrm{DEC}=9.9$ and methyl salicylate $\mathrm{DEC}=9$ ), an appreciable decrease in ZP from $-82 \mathrm{mV}$ (for p-cresol) to $-27 \mathrm{mV}$ (for methyl salicylatc) is noteworthy. $p$-Cresol which belongs to phenolic group of compounds tends to dissociate in the presence of water and forms intermolecular hydrogen bonds with water molecules. These two phenomena should contribute to the high electronegative $Z P$ observed. In methyl salicylate the lower $Z P$ value may be attributed to its strong intramolecular hydrogen bonding and the feeble dipole interaction. The interaction of $p$-cresol and methyl salicylate with water can be confirmed from the stability behaviour of their respective emulsions. $p$-Cresol emulsion was comparatively more stable than methyl salicylate emulsion (table 3). The higher stability of p-cresol emulsion over methyl salicylate emulsion may be because of the combined elfect of dipole accumulation and higher ZP. Increased dipole accumulation at oil-water interphase might have formed a complex condensed film of dipoles over globules, which should possibly prevent the coaguiation of globules of p-cresol, primarily by the higher repulsive energy barriers due to higher electronegative ZPP and later due to the rigidity of film of hydration in such a system.

Studies (Roberts 1936; Carruthers 1938; Growney 1941; Dickinson 1941) have earlier been carried out to evaluate the structural effect of internal phase on the EM (ZP is a direct function of EM). March $(1927,1935)$ believed that the stability source of an oil-hydrosol (o/w emulsion without emulsifier) is the "protective aqueous skin" around the dispersed particle. According to Mueller (1935) water molecules get attracted to the globule surface in the oil-hydrosols by electrostatic forces of double layer and hence their stabilizing influence diminishes as ZP becomes smaller. Therefore, it is generally agreed that both charge and hydration effects are important in the stability of emulsions without emulsifier against coalescence.

An approximate relationship between the DEC of internal phase and ZP indicates that not only the internal phase polarity but also the extent of dissociation of chemical groups present on globule surfaces and their specific interactions with dispersion medium are the factors governing $Z \mathrm{P}$. If this mechanism is operating at interphases, 
Table 3. Stability scores, average globulc sizo and ioterfacial areas of $o / w$ emulsions containing internal plases of varying polarities.

\begin{tabular}{|c|c|c|c|c|c|c|c|}
\hline \multirow[b]{2}{*}{ Internal phase } & \multirow[b]{2}{*}{$\begin{array}{l}\text { Internal } \\
\text { phase } \\
\text { DEC }\end{array}$} & \multicolumn{2}{|c|}{$\begin{array}{l}\text { Emulsions without } \\
\text { emulsifier }\end{array}$} & \multicolumn{2}{|c|}{$\begin{array}{l}\text { Emulsions with } \\
\text { emulsificr }\end{array}$} & \multirow[b]{2}{*}{$\begin{array}{l}\text { Average } \\
\text { globule } \\
\text { sice ( } \mu m \text { ) }\end{array}$} & \multirow[b]{2}{*}{$\begin{array}{c}\text { Interfacjal } \\
\text { area } \\
\left(\mathrm{cm}^{2} / \mathrm{rol}\right)\end{array}$} \\
\hline & & $\begin{array}{l}\mathrm{ZP} \text { in } \\
(\mathrm{mV})\end{array}$ & $\begin{array}{c}\text { Stability } \\
\text { score }\end{array}$ & $\begin{array}{l}\mathrm{ZP} \text { in } \\
(\mathrm{mV})\end{array}$ & $\begin{array}{c}\text { Stability } \\
\text { score }\end{array}$ & & \\
\hline$p$-cresol ${ }^{5}$ & 9.9 & $-82-08$ & 5 & -4468 & 1 & - & - \\
\hline Dichlorometlane ${ }^{1}$ & $9 \cdot 1$ & - & 0 & -558 & 1 & - & $=$ \\
\hline Methylsalicylatc ${ }^{6}$ & 9 & $-28 \cdot 35$ & 4 & -4262 & 4 & 3.02 & 6555 \\
\hline Anilina $0^{1}$ & 6.879 & - & 0 & -63.00 & 1 & - & - \\
\hline Methyl benzoate ${ }^{1}$ & 6.5 & $-41 \cdot 84$ & 4 & $-36 \cdot 2$ & 4 & $2 \cdot 92$ & 6817 \\
\hline Lauryl alcohol' & 605 & -- & 0 & -330 & 3 & $2 \cdot 103$ & 9204 \\
\hline Chlorobenzene $^{7}$ & 5.54 & -37.8 & 4 & $-36 \cdot 15$ & 4 & $3 \cdot 02$ & 6555 \\
\hline Chloro[orm ${ }^{1}$ & $5 \cdot 2$ & - & 0 & $-34 \cdot 16$ & 1 & -- & - \\
\hline Amyl benzoate ${ }^{1}$ & 4.98 & - & 0 & $-15-4$ & 4 & 3.78 & 5237 \\
\hline Anyl actetate & 4.834 & - & 0 & -1978 & 4 & $2 \cdot 747$ & 7372 \\
\hline Trichlorobenzene ${ }^{1}$ & 4.68 & $-30+06$ & 4 & $-21+48$ & 4 & $2-38$ & 8.320 \\
\hline Castor oil ${ }^{4}$ & 4.57 & $-41 \cdot 12$ & 4 & -25.96 & 5 & 5.93 & 3399 \\
\hline Anisole ${ }^{9}$ & $4 \cdot 4$ & -- & 0 & $-30 \cdot 34$ & 5 & $4 \cdot 13$ & 4812 \\
\hline Coconut oil ${ }^{+}$ & 3.315 & $-20 \cdot 73$ & 4 & -19.54 & 5 & 3.406 & 5815 \\
\hline Linsced oint & $3 \cdot 26$ & $-51 \cdot 6$ & 4 & -3425 & 5 & 2935 & 6742 \\
\hline Isopropylmyristate ${ }^{9}$ & 3.219 & $18 \cdot 29$ & 4 & $-18 \cdot 52$ & 5 & 2214 & 9028 \\
\hline Cottot seed oil ${ }^{*}$ & $3 \cdot 18$ & $-27 \cdot 45$ & 4 & $-19 \cdot 48$ & 5 & 2.803 & 7062 \\
\hline Sunllower oil ${ }^{4}$ & $3 \cdot 13$ & $-19 \cdot 69$ & 4 & -19.7 & 5 & 3.43 & 5454 \\
\hline Sesatme oll & $3 \cdot 139$ & -17.98 & 4 & $-23 \cdot 62$ & 4 & $2 \cdot 815$ & 7033 \\
\hline Arachis oil ${ }^{4}$ & $3 \cdot 12$ & $-29 \cdot 61$ & 4 & $-23 \cdot 12$ & 5 & 3.595 & $\$ 502$ \\
\hline Olive oil10 & $3 \cdot 1$ & $-24 \cdot 43$ & 4 & -21.45 & 5 & 37 & 5351 \\
\hline Mustard oi] $]^{4}$ & $3 \cdot 053$ & $-18 \cdot 48$ & 4 & -20.79 & 4 & 3.516 & 5631 \\
\hline$m-x y l e n e^{1}$ & $2 \cdot 555$ & - & 0 & $-24 \cdot 81$ & 4 & $2 \cdot 243$ & $8 \nsubseteq 22$ \\
\hline Oleic acid & $2 \cdot 44$ & $-15 \cdot 63$ & 1 & $-18+1$ & 1 & - & - \\
\hline Xуleле ${ }^{2}$ & $2 \cdot 40$ & $-14 \cdot 2$ & 1 & $-10-96$ & 4 & 4.82 & 4108 \\
\hline Toluene & $2 \cdot 30$ & - & 0 & $-12 \cdot 6$ & 3 & $2-76$ & 7173 \\
\hline \multirow{2}{*}{\multicolumn{8}{|c|}{ Carbon tetra }} \\
\hline & & & & & & & \\
\hline chloride & $2 \cdot 20$ & - & 0 & -17.60 & 1 & - & $\cdots$ \\
\hline Benzene & $2 \cdot 20$ & $-27 \cdot 37$ & 1 & $-16 \cdot 04$ & 3 & 302 & 6600 \\
\hline Lemon oil ${ }^{13}$ & $2 \cdot 20$ & $-13 \cdot 10$ & 1 & $-11 \cdot 00$ & 1 & - & - \\
\hline Turpentine oil $^{12}$ & $2-20$ & -17.81 & 1 & $-19 \cdot 60$ & 3 & 2.655 & 7449 \\
\hline Liq̣uid peralfiri ${ }^{4}$ & $2 \cdot 15$ & $-25 \cdot 15$ & 4 & $-25 \cdot 26$ & 5 & $8 \cdot 30$ & 2385 \\
\hline Cyclohexanes $^{5}$ & $2-02$ & $-14 \cdot 48$ & : & -1280 & 3 & $3 \cdot 12$ & 6346 \\
\hline n-Octane & $1-948$ & - & 0 & -10.78 & 3 & 348 & 5689 \\
\hline iso-Octane ${ }^{\sigma}$ & $1 \cdot 94$ & $-19 \cdot 72$ & 1 & -11.64 & 3 & 264 & 7489 \\
\hline n-heptane & $1 \cdot 924$ & -18.29 & 1 & -15.47 & 3 & 295 & 6716 \\
\hline n-hexane & $4-896$ & $-18 \cdot 11$ & 1 & $-18 \cdot 5$ & 3 & 2.99 & 6621 \\
\hline
\end{tabular}

1. Britist Diug House, India; 2. Sisco Chemicals, Indja: 3. Sigma Chemical Company, St. Louis MO, USA; 4. Deepti Pharmaceuticals, Nagpur, India; 5. Plizer, India Ltd; 6. Sarab hai M Chemicals, India; 7, Imported from USSR; 8. Bust, London, England; 9. Fluka, Switrerland; 10. Imported from Italy, supplied by Vikts Pharma, India; 11. St. Bernard, London; 12. I J Chemical, Nagpur, Indja.

it seems probable that $Z \mathrm{P}$ and stability of emulsions containing non-polar internal phase could be enhanced, provided they are contaminated with any dipole-orienting molecule. This effect has been verified experimentally in hexane-in-water emulsions, where 1 and $10 \%$ of hexanol were incorporated in $n$-hexane and emulsions werc 


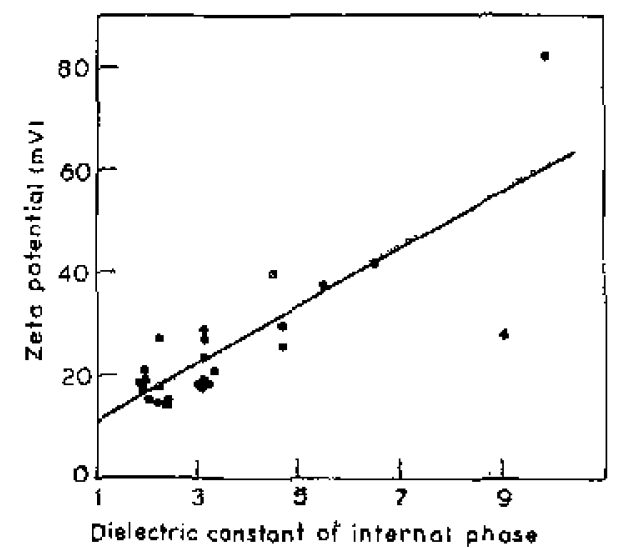

Figure 1. Effect of DEC of interna! phise on ZP of o/w emulsions prepared without using any emulsifier.

Table 4. Zeta potential and stability thanges due to the addition of $n$-hexanol to the internal phase of m-hoxanein-warce emtalsions prepared without usitg enulsifier.

\begin{tabular}{|c|c|c|c|}
\hline \multicolumn{2}{|c|}{ Internal phase } & \multirow[b]{2}{*}{$\mathrm{ZP}$ in $\mathrm{mV}$} & \multirow[b]{2}{*}{ Stability score } \\
\hline $\begin{array}{l}n \text {-hexanol } \\
\% \psi *-\gamma\end{array}$ & $\begin{array}{c}\text { n-hexane } \\
\% \mathrm{y} / \mathrm{v}\end{array}$ & & \\
\hline 0 & 100 & -12 & I \\
\hline 1 & 99 & -18 & 4 \\
\hline 10 & 90 & -21 & 4 \\
\hline 100 & 0 & -26 & 4 \\
\hline
\end{tabular}

formed without using any emulsifier. As expected (table 4), erhulsions of $n$-hexane (hexanol)-in-water have shown an increase in their ZP and stability with increasing concentrations of hexanol.

Changes in ZPs of emulsions prepared with polysorbate- 80 using internal phases of varying DECs are illustrated in figure 2. Similar to that of emulsions without emulsifier, in these systems too, there is an increase in ZP with increasing DEC of internal phase and correlation between $\mathrm{DEC}$ of internal phase and $\mathrm{ZP}$ is approximate $(r=0.8389 ; n=35, p<0.01$ ). However, the presence of polysorbate- 80 in these systems lowered the magnitude of ZP. Lowering the magnitude of ZP in the presence of polysorbate-80 is in accordance with eartier observations (Elworthy and Florence 1969; Riddick 1970).

Although there is considerable variation in the ZP values of all the 37 emulsions formed with various internal phases, their glabule size and IA changes are limited (table 3). No relation could be traced between ZP and IA and this factor as also the existence of an approximate relationship between $Z \mathrm{P}$ and $\mathrm{DEC}$ of intemal phase show, internal phase polarity as the probable factor influencing $Z P$.

$Z P$ is the potential at the surface separating the immobile part of the double layer (stern layer) from the diffuse part. It is a simultaneous measure of the charge density 


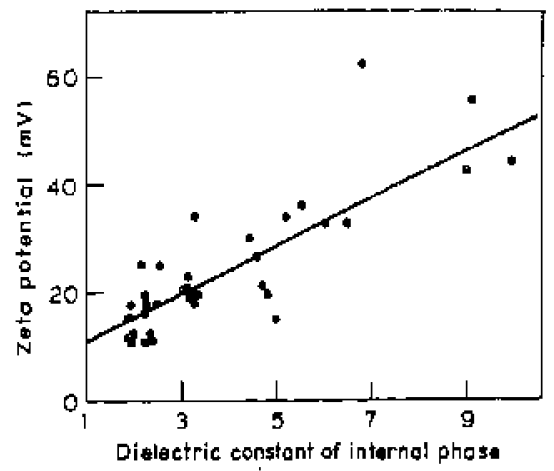

Figure 2. Effect of DEC ol internal phase on ZP of $0 / \mathrm{w}$ emulsions prepared with polysorbate 80.

of diffuse double layer (per unit surface of the globule of a particuiar internal phase) and also the extent to which it extends from the sufface (Riddick 1968). Thus, it would depend on the mode of orientation of emulgent molecules and the number of such molecules present at the unit surface. Ottewill (1967) proposed different modes of orientation of non-ionic surfactant molecules with changing polarity of the dispersed phase in a solid/liquid dispersion. His concept as applied to present liquid/liquid dispersions (emulsions stabilized with polysorbate-80) cannot explain the increase in ZP with increase in polarity of internal phase. According to this concept, on relatively polar internal phases the orientation is through oxy-ethylene chain so that the charge conferring groups of polysorbate-80 are now engaged in the interaction with globule surface. We therefore believe that not oniy the internal phase DEC but surface ionogenicity, interaction of internal phase with water dipoles and mode and extent of orientation of emulgent are factors that govern the ultimate double layer structure and its charge density. As all of them contribute in a complex way to increase ZP with increasing internal phase polarity, it would be futile to explain this effect only through a single factor such as the changes of mode of orientation with a change in polarity of internal phase.

In table 3, the stability behaviour of emulsions made with or without emulsifier is recorded. Tn the case of emulsions without emulsifier, internal phases with lower DECs (DEC of internal phase $=1.89$ to 2.55 ) formed emulsions which had comparatively lower stability than that of emulsions formed with internal phases having higher DECs (DEC of internal phase $=3$ to 10 ). A similar trend was observed in emulsions made with polysorbate-80, the only exception being that they were comparatively more stabie than emulsions without emulsitier.

In emulsions with or without emulsiiner, the relationship between DEC of internal phase and ZP was found to be approximate. This was attributed to the wide variation in the chemical nature of internal phase. To obviate this factor and to understand clearly the influence of DEC of internal phase on ZP, internal phases belonging to the homologous series of saturated aliphatic hydrocarbons were chosen. As can be seen Irom figure 3, with increase in hydrocarbon chain length there is an increase in IA and decrease in $Z P$ of emulsions. In figure $4, Z P$ is plotted against $D E C$ of internal phase. They exhibit a fairly good inverse correlation between them $(r=0.9738$, at $n=3$; at $p<0.01)$. Thus, in homologous series $\mathrm{ZP}$ is an inverse function of DEC of internal phase. 


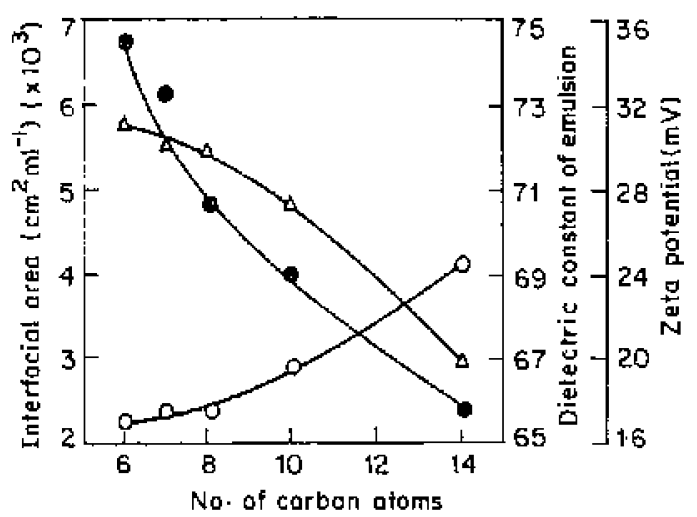

Figure 3. Changes in ZP, interfacial area and DEC of o/w emulsions prepared with polysorbate- 80 due to the change in the carbon chain length of internal phase constituting these emu]sions. O-O IA; $\Delta-\Delta$ PEC;

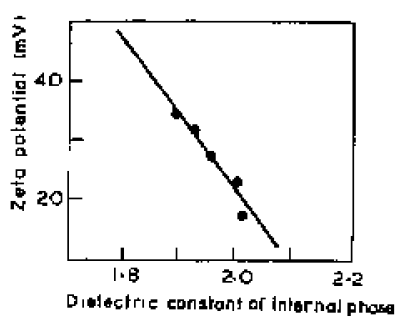

Figure 4. Relationship between DEC of internal phase and ZP of $\mathrm{o} / \mathrm{w}$ ernulsions prepared with polysorbate-80. Internal phases constituting these emulsions belong to the homologous series of aliphatic hydrocarbons.

Changes in IA do not decisively explain ZP changes since for a meagre change in IA in $\mathrm{C}_{6}$ to $\mathrm{C}_{8}$ hydrocarbon emulsions, there is a considerable drop in $Z \mathrm{P}$ from -35 to $-27 \mathrm{mV}$ (figure 3 ).

The increase in ZP with decrease in carbon chain length may be attributed to the increased interfacial adsorption of polysorbate- 80 . Consequently the stability of emulsions made with hydrocarbons of shorter chain lengths should be greater compared to the longer ones. Although we did not perform long-term stability studies of these emulsions, we presume that ZP may decisively control stability, as in these systems no parameter other than the surface coverage contributes to ZP. Davis and Smith (1972) also observed that the stability of emulsions of $C_{6}$ to $C_{16}$ hydrocarbons prepared with sodium dodecyl sulphate falls progressively as the alkane chain length is increased. Within the homologous series they reported an inverse correlation between DEC of internal phase and stability.

Increase in phase volume ratio from 0.05 to 0.30 brought about a meagre drop in $Z P$ whereas a further increase in phase volume ratio brought about a considerable drop (figure 5). With increasing phase volume ratio, there is a steady increase in IA. The characteristic slow decrease in ZP up to a phase volume ratio of 0.30 and later the rapid decay can be explained by considering the emulgent concentration in relation to the total IA which is to be covered in these systems. An emulsion with a phase volume ratio of 0.75 yielded the largest IA. One gram per cent of emulgent used in 


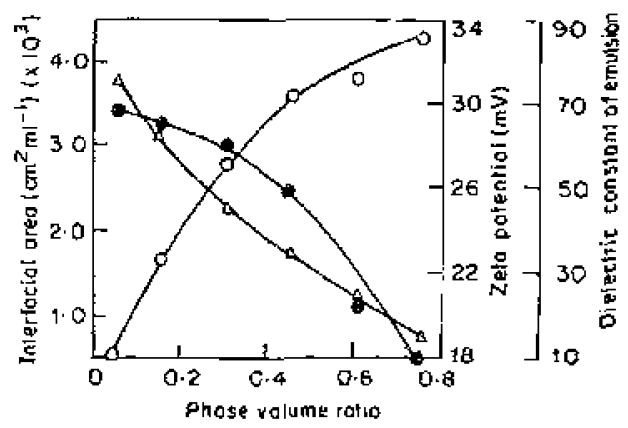

Figure 5. Eflect of phase volume ratio on $2 \mathrm{P}$ interfacial area and $\mathrm{DEC}$ df $\mathrm{o} / \mathrm{w}$ emulsions prepared with polysorbate-80. O-O IA; $\Delta-\Delta$ DEC; - ZP.

the study confers a certain amount of charge to its globules, taking the ZP value to $-18 \mathrm{mV}$ (figure 5). As IA is decreased by decreasing the phase wolume ratio, the same amount of emulgent would now cover a larger surface area per globule increasing the charge density per globule. However, once the globule surface is completely covered with a monolayer, there is hardly any more forcing of emulgent molecules to interlace and thus, the $\mathrm{ZP}$ changes are limited. A monolayer adsorption seens to have occurred in emulsions having a phase volume ratio of $0-30$. In emlulsions with phase volume ratio less than 0.30 aiso, monolayer is formed and thus they are expected to show limited changes in ZP. Limited changes in ZP of the disperse systems after a monolayer adsorption at liquid-liquid interface or solid-liquid interiace have been reported earlier (Nash and Hacger 1966; Ottewill 1967; Riddick 1968).

\section{Effect of properties of internal phase on DEC of o/w emulsion}

From theoretical postulations, a relationship between DEC of internal phase and DEC of emulsion is expected. However such a relationship does not appear to exist. $(r=02463 ; n=35$, at $p<0.01)$ in emulsions prepared with polysotbate-80 (table 5). Further, it is obvious that the observed DECs of emulsions are higher than the values computed from any equation. Any enhancement of the observed DEC of emulsions over the theoretically computed value was attributed to either double-layer polarization or the degree of dispersion. According to Piekara (1932a, b), in emulsions stabilized by emulgents, smaller the globule size (i.e. higher the total IA per ml of emulsion), higher is the degree of dispersion and greater is its value of DEC. Since in the present systems no relationship is exhibited between DEC of emulsion and IA, it is difficull to substantiate the role played by dispersion in these systems: Thus, the enhanced values of $\mathrm{DECs}$ of emulsions may be due to the effect of double-layer polarization. The influence of polarization of electrical double layer on DEC of emulsions was noted by Frieke and Curtis (1937). According to them, when a dielectric dispersed in water is subjected to an electric field, a part of the current passes through the sysiern at interfaces and the system becomes partly polarized. Dielectric properties of such systems are quite different from what would be expected from the contribution of two-component phases. As this view received much support (Piekara 1932; Fraơkina 1950; Schwan 1951, 1968; Dukhin 1971) Dukhin (1971) felt that the elevated DECs 
Table 5. Calculated and observed DEC of o/w emulsions prepared with polysorbate-80.

\begin{tabular}{|c|c|c|c|c|c|c|c|}
\hline \multirow[b]{3}{*}{ Internal phase } & \multirow{3}{*}{$\begin{array}{c}\text { Internal } \\
\text { phasc } \\
\text { DEC }\end{array}$} & \multicolumn{6}{|c|}{ DECs of emulsions } \\
\hline & & \multicolumn{6}{|c|}{ Calculated from equations of } \\
\hline & & Rayleigh & Wiener & Bruggeman & Bottcher & Hanai & Observed \\
\hline p-Cresol & 9.9 & 4883 & $49 \cdot 21$ & $48: 38$ & 46.67 & 48.65 & 28.46 \\
\hline Dichloromethane & $9-1$ & $48: 41$ & $48 \cdot 81$ & 47.92 & 4613 & $48 \cdot 11$ & 61.67 \\
\hline Methyl salicylate & $9-0$ & $48 \cdot 35$ & $48 \cdot 75$ & 47.86 & $46-65$ & 48.04 & $59 \cdot 71$ \\
\hline Aniline & $6-87$ & 47.73 & 47.92 & $46 \cdot 48$ & 44.68 & $46 \cdot 75$ & 53.2 \\
\hline Methyl benzoate & $6 \cdot 5$ & 46.98 & $47 \cdot 48$ & $46 \cdot 38$ & 44.22 & $46 \cdot 34$ & 53.95 \\
\hline Lau yl alcohol & 6.05 & 4673 & $47 \cdot 23$ & $46 \cdot 11$ & $43-87$ & 4604 & 51.94 \\
\hline Chlorobenzene & $5+54$ & $46 \cdot 45$ & 46.96 & 45.79 & $43 \cdot 47$ & $45 \cdot 76$ & $54 \cdot 4$ \\
\hline Chlorotorm & $5 \cdot 2$ & $46 \cdot 2$ & $46 \cdot 73$ & $45 \cdot 5$ & $43 \cdot 12$ & $45 \cdot 4$ & $53 \cdot 24$ \\
\hline Amyl acetate & $4 \cdot 83$ & 45.99 & $46 \cdot 61$ & $45 \cdot 38$ & 42.87 & $45 \cdot 23$ & 51.66 \\
\hline Anyl herroate & 4.98 & $46 \cdot 04$ & $46-65$ & $45 \cdot 45$ & 42.98 & $45 \cdot 31$ & $50 \cdot 38$ \\
\hline Trichloro benzene & $4 \cdot 68$ & $46 \cdot 2$ & $46 \cdot 73$ & 45.26 & $43 \cdot 12$ & $45 \cdot 11$ & $49 \cdot 44$ \\
\hline Cestor oil & $4 \cdot 57$ & 45.96 & $46 \cdot 45$ & $45 \cdot 19$ & $42 \cdot 69$ & $45 \cdot 04$ & $53 \cdot 2$ \\
\hline Antisole & $4 \cdot 4$ & 45.81 & $46 \cdot 36$ & $45 \cdot 02$ & 42.56 & $44 \cdot 93$ & $54 \cdot 1$ \\
\hline Coconut oil & $3 \cdot 3 \mathrm{I}$ & $45 \cdot 78$ & $45 \cdot 78$ & $44 \cdot 4$ & $4 \mathrm{~L} \cdot 65$ & $44 \cdot 19$ & $53-24$ \\
\hline Litnseed oil & 326 & $45 \cdot 19$ & $45 \cdot 78$ & 4437 & $41 \cdot 61$ & $44 \cdot 19$ & $55-95$ \\
\hline Isopropyl myristate & 3.2 & $45 \cdot 1$ & $45 \cdot 73$ & 44.34 & 41.58 & $44 \cdot 12$ & $50 \cdot 65$ \\
\hline Cottonseed bit & $3 \cdot 18$ & 4509 & $45+71$ & $44 \cdot 32$ & $41 \cdot 34$ & $44: 1$ & $53+13$ \\
\hline Sumllower oil & $3 \cdot 13$ & 4508 & $45 \cdot 68$ & 4429 & $41 \cdot 29$ & $44 \cdot 06$ & $53 \cdot 48$ \\
\hline Sosame oil & $3 \cdot 13$ & 4508 & $45-69$ & 4429 & $41 \cdot 3$ & $44 \cdot 07$ & 6000 \\
\hline Arachis wil & $3 \cdot 12$ & 4507 & $45 \cdot 68$ & $44 \cdot 28$ & $41 \cdot 28$ & $44 \cdot 05$ & $51 \cdot 94$ \\
\hline Olive oil & $3 \times 1$ & 4507 & $45 \cdot 67$ & $44 \cdot 27$ & $41 \cdot 76$ & $44 \cdot 0$ & $52 \cdot 6.3$ \\
\hline Mtsstard oil & 305 & $45 \cdot 06$ & $45 \cdot 64$ & $44 \cdot 24$ & $41 \cdot 22$ & $44 \cdot 01$ & 58.7 \\
\hline$m$-Xylene & $2 \cdot 55$ & $44 \cdot 75$ & $45 \cdot 37$ & 43.92 & $40-98$ & $43 \cdot 67$ & $52 \cdot 62$ \\
\hline Oleic acid & 244 & $44 \cdot 71$ & $45 \cdot 31$ & 43.85 & $40-88$ & $43 \cdot 59$ & $59 \cdot 33$ \\
\hline Xylene & 24 & $44 \cdot 68$ & $45 \cdot 29$ & 43.82 & 40.86 & $43 \cdot 57$ & $52 \cdot 24$ \\
\hline Toulene & $2 \cdot 30$ & 44.05 & $45 \cdot 24$ & $43 \cdot 75$ & $40 \cdot 77$ & $43 \cdot 5$ & $51 \cdot 29$ \\
\hline$p$-Xylene & $2 \cdot 23$ & $44 \cdot 58$ & $45 \cdot 2$ & 43.71 & $40 \cdot 71$ & $43-45$ & $45 \cdot 75$ \\
\hline $\begin{array}{c}\text { Carbon tetra } \\
\text { ahloride }\end{array}$ & $2 \cdot 2$ & 44.55 & $45 \cdot 18$ & 4369 & $40-69$ & $43+43$ & 53.75 \\
\hline Benzenc & 220 & $44 \cdot 55$ & 4518 & $43+69$ & $40 \cdot 69$ & $43 \cdot 43$ & $51 \cdot 05$ \\
\hline Lemon oil. & 220 & 44.55 & $45 \cdot 18$ & $43 \cdot 69$ & $40 \cdot 69$ & $47 \cdot 43$ & $49 \cdot 35$ \\
\hline Turpentine oil & $2: 2$ & $44 \cdot 55$ & $45 \cdot 18$ & $43+69$ & $40 \cdot 69$ & $43 \cdot 43$ & $53 \cdot 00$ \\
\hline Liquid parafirn & $2 \cdot 15$ & 44.51 & $45 \cdot[6$ & $43-59$ & $40 \cdot 64$ & $43 \cdot 4$ & $51 \cdot 05$ \\
\hline Cyclohexane & 202 & $44 \cdot 45$ & 45.09 & $43-57$ & $40-52$ & $43-31$ & 47.97 \\
\hline n-Oetane: & 1.95 & $44 \cdot 40$ & $45 \cdot 05$ & $43 \cdot 53$ & $40-46$ & $43 \cdot 26$ & $50-28$ \\
\hline iso-Octatie & 1.94 & 44,38 & 45.05 & $43-53$ & $40-46$ & $43 \cdot 26$ & $48 \cdot 85$ \\
\hline n-Heptare & 1.92 & 4435 & $45 \cdot(14$ & $43+51$ & $40-42$ & $43 \cdot 25$ & $50-56$ \\
\hline n-Hexanc & 1.89 & 4432 & 4502 & $43 \cdot 49$ & $40-41$ & $43 \cdot 22$ & $50-48$ \\
\hline
\end{tabular}

of emulsions are due to the double-layer polarization and proposed a theory somewhat similar to that of Fricke and Curtis. According to this theory, under the influence of an external field, tangential fluxes of diffused double-layer jons arise and are redistributed along the particle surface in a dispersed system. The double layer is thus deformed and polarized, deviating from the initial spherical structure. This theory was verified with few experiments (Schwan 1951, 1968). Dukhin therefore states that the theory of diffuse double-layer polarization and its effect on DEC of dispersion 


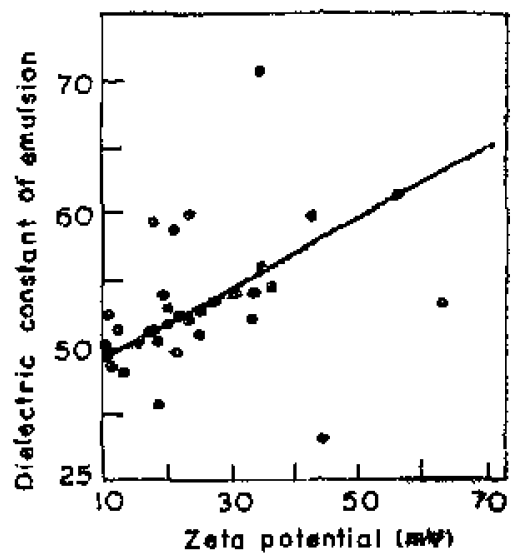

Figure 6. Plot of emulsion versus $2 \mathrm{P}$ for o/f emulsions, containing internal phases of varying polarity being pecpared using polysorbate- 80 .

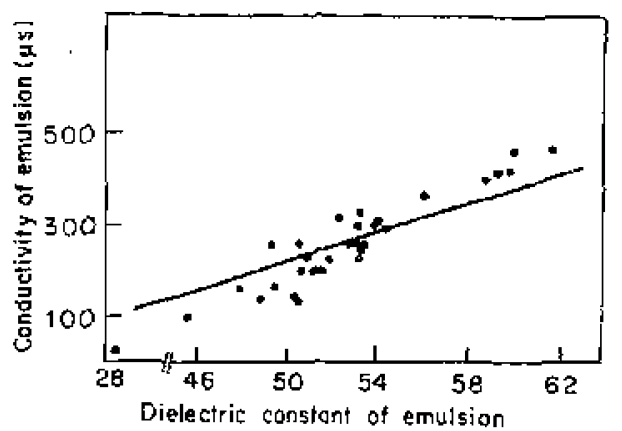

Figure 7. Plot of conductivity of emulsion versus DEC of o/ emulsion prepared with polysorbate-80.

being in good agreement with experiments, deserves further allround verification. We have therefore explored the possible relationship between DEC of emulsion and diffuse double-layer potential (ZP). Dielectric constants of emulsions (prepared with polysorbate-80) are plotted against $\mathrm{ZP}$ in figure 6 . The correlation coefficient value $(r=0.91 ; n=35$, at $p<0.01)$ suggests that the relation between DEC of emulsion and $Z P$ is approximate.

To examine the probable cause of scattering, the conductivity of emulsion was measured (figure 6). Figure 7 is a plot of conductivity versus DEC of emulsion. The relation between these two parameters is also approximate $(r=0.854 ; n=35$, at $p<0.01$ ). It may be deduced that $Z P$ which is a parameter whose value depends upon interfacial characters of emulsion, is not affected by the changes in conductivity which would rather depend upon the bulk properties of emulsion. Therefore, the measurement of conductivity along with DEC should always be emphasized as it could give valuable information regarding the dielectric properties of emuisions.

Because of the diversity in the chemical nature of internal phases, the relation between DEC and ZP could be approximate. A specific chemical group such as homologous series of aliphatic hydrocarbons was therefore chosen to obviate such 
Table 6. Effect of carbon chain length on globule size and DEC of emulsions.

\begin{tabular}{|c|c|c|c|c|c|c|c|c|}
\hline \multirow{3}{*}{$\begin{array}{l}\text { Internal } \\
\text { phase }\end{array}$} & \multirow{3}{*}{$\begin{array}{c}\text { DEC of } \\
\text { internal } \\
\text { phase }\end{array}$} & \multirow{3}{*}{$\begin{array}{l}\text { Average } \\
\text { globule size } \\
\text { (in } \mu \mathrm{rr} \text { ) }\end{array}$} & \multicolumn{6}{|c|}{ DECs of emulsions } \\
\hline & & & \multicolumn{6}{|c|}{ Calculated from cquations of } \\
\hline & & & Rayleigh & Wiener & Botteher & Hanai & Bruggeman & Observed \\
\hline H-Hexane & 1.89 & $2 \cdot 665$ & $66 \cdot 207$ & $66 \cdot 21$ & $67 \cdot 102$ & $65-987$ & 6603 & 726 \\
\hline n-Heptane & $1-924$ & $2 \cdot 606$ & $66 \cdot 217$ & 66.217 & $67 \cdot 107$ & $65-995$ & 66.037 & 7201 \\
\hline n-Octane & $1-948$ & 2.462 & 66.222 & 66222 & 67111 & 660000 & 66.042 & 72.01 \\
\hline n-Decane & 2.004 & 2.049 & 66.233 & 66.233 & 67121 & $66 \cdot 012$ & 66054 & $70 \cdot 76$ \\
\hline $\begin{array}{l}\text { N-Tetra } \\
\text { decane }\end{array}$ & $2-036$ & 1.842 & $665 \cdot 239$ & $66 \cdot 239$ & $67 \cdot 126$ & 66019 & 66061 & 66.88 \\
\hline
\end{tabular}

an effect. Figure 3 shows the dependence of parameters such as ZP, DEC and IA of emulsions on the carbon chain length of internal phase.

The DEC values of aliphatic hydrocarbons increase with increasing carbon chain length (table 6). The DECs of emulsions observed decrease with increasing DEC of internal phase. This contradicts with the theoretical postulations. The DEC values obtained experimentally are considerably higher than the values calculated from equations (1) to (5) (table 6).

Interfacial area and DEC of emulsion show excellent inverse correlation between them $(r=-0.9959 ; n=3$, at $p, 0.01)$ (figure 8A). Tetra-decane emulsion exhibits the lowest average particle size and highest IA in the series. Increasing the carbon chain length from $\mathrm{C}_{6}$ to $\mathrm{C}_{14}$ causes limited change in the average particle size. The lowest DEC value (for tetradecane emulsion) being associated with an emulsion having smallest average particle size appears in contradiction to the earlier observations by Piekara (1932a, b), who found that in concentrated emulsions (enulsion containing emulgents) smaller the globule size, greater is the DEC. The relation between ZP and DEC of emulsion is difficult to linearize (figure $9 \mathrm{~A}$ ). But a linear correlation between DEC and ZP is revealed $(r=0.9594 ; n=3$, at $p<0.05)$ when the difference between the obserwed and theoretical DEC (obtained from Bruggeman equation) is plotted against ZP (figure 10).

From the above two studies it can be substantiated that the higher observed values of DEC of emulsions as compared to the theoretical one may be due to the double-layer polarization in these systems. Therefore it can be stated that adsorption of emulgent has a profound influence on the DEC of emulsion. This confirms the reports from Piekara (1932) and Fricke and Curtis (1937). Hanai et al (1962) stated that in o/w emulsions, the double-layer polarization is negligible and if at all envisaged can only occur, provided the internal phase has high DEC or conductivity. However the present observations indicate that the changes in bulk properties such as DEC of internal phase may not be directly responsible for double-layer polarization, but ultimately it may depend on the surface properties such as mode of emulgent orientation, extent of emulgent adsorption and its capability of interaction with bulk medium. These effects have profound influence on diffuse double-layer polarization, and hence $\mathrm{DEC}$ of disperse systems can be characterized by not only the bulk properties but also to a considerable extent by surface properties.

Increasing the phase volume ratio from 0.05 to 0.75 causes a steady decrease in 


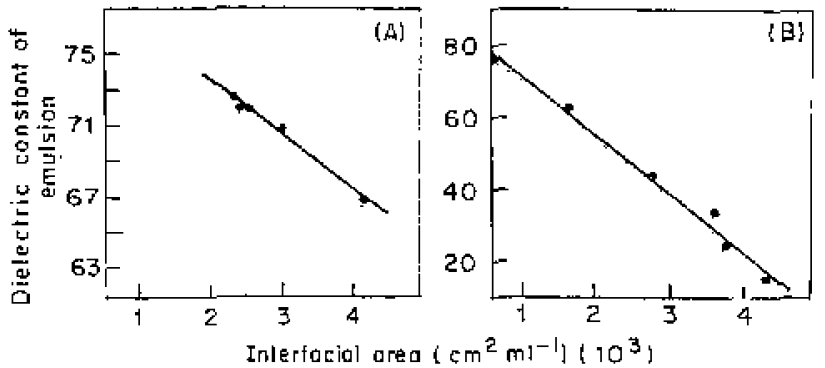

Figure 8. Relation between DEC of enulsion and interfacial area per ml of mulsion. $A$, study pertaining to homologous series; $\mathbf{B}_{1}$ study perlaining to phase volume ratio,

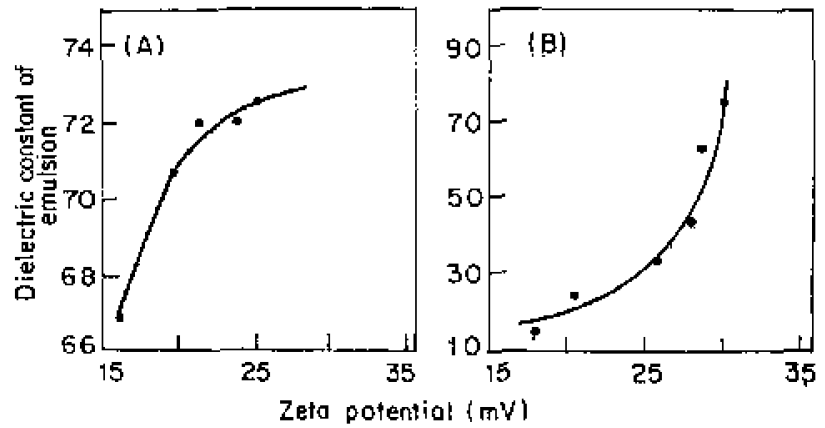

Figure 9. DEC plot of emulsion vs ZI. A, study pertaining to a homologous series, B, study pertaining to phase volume ratio.

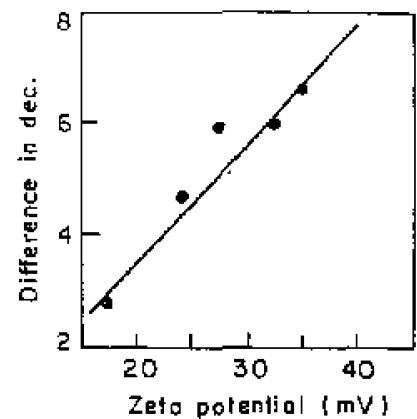

Figure 10. Relation between DEC and ZP of o/w emulsion prepared with polysorbate-80, where the difference between the observed DEC of emulsion and theoretical DEC compulad by Bruggetman equation is plotted against ZP for o/w emulsion containing internal phases belonging to homologous series.

DEC of emulsion (figure 5). This agrees with earlier reports (Hanai 1959, 1961), Of ail the equations, the Bruggeman equation appears to predict the observed values more accurately (table 7). Similar view was expressed by Hanai (1960).

Increase in phase volume ratio brought about a steady decrease in the DEC of emulsion and an increase in IA (figure S). Since DEC and IA are the functions of phase volume ratio, a relation between these parameters can be expected. When $\mathrm{DEC}$ 
Table 7. Effect of phane volume ratio on DEC of emulsions.

\begin{tabular}{|c|c|c|c|c|c|c|}
\hline \multirow{2}{*}{$\begin{array}{l}\text { Pliase } \\
\text { volume } \\
\text { ratio }\end{array}$} & \multirow[b]{2}{*}{ Observed } & \multicolumn{5}{|c|}{ DECs of emulstons } \\
\hline & & Bruggeman & Hanai & Bottcher & Wiener & Rayleigh \\
\hline 005 & $76 \cdot 13$ & 71.3783 & $71 \cdot 29$ & 71.28 & $71 \cdot 30$ & $71 \cdot 39$ \\
\hline $0 \cdot 15$ & 63.38 & 60.9543 & $53 \cdot 3$ & 6094 & $61 \times 2$ & 61.8 \\
\hline 0.30 & 44.56 & $46 \cdot 54291$ & $35-51$ & $45 \cdot 76$ & 4892 & 48.55 \\
\hline 0.45 & 33.92 & $33-3599$ & $22-62$ & $3 J \cdot 40$ & 37.92 & $3,5-52$ \\
\hline 0.60 & $24 \cdot 76$ & 21.9329 & $14-07$ & 25.98 & $27 \cdot 26$ & $20 \cdot 72$ \\
\hline 0.75 & $15+11$ & I $2 \cdot 4238$ & 0.22 & $18-23$ & 18.08 & $4 \cdot 34$ \\
\hline
\end{tabular}

and IA were plotted in figure $8 \mathrm{~B}$ an excellent inverse correlation was observed $(r=-0.9949 ; n=4$, at $p<0.01)$. However $Z P$, a parameter which is a function of IA, showed an empirical relation with DEC (figure 9B). Therefore ZP changes seem to have limited importance in explaining the changes in DEC with alteration in phase volume ratio.

All the equations ((1)-(5)) employed by us to predict the DECs of emulsions under changing phase volume ratios predict the observed DECs of exnulsions with some accuracy. But they fail to predict DEC values of emulsions under the changing DEC of internal phase, where phase volume ratio was kept constant. It may therefore be stated that the applicability of these equations is limited to the condition in which internal phase concentration is varied keeping DEC of internal phase constant.

\section{References}

Bijsterbosch B H und Lykiema J 1967 Proc. Forrth Inr. Congr. Surface Activity Brussels (London: Gordon and Breach)

Bockris J O M. Dewanathan M A Y and Mutter K 1963 Proc. R. Soe (Londond A274 55

Bottcher C J F 1952 Theory of electric poldrization (New York: Elsevier) $\mathrm{p} 419$

Butuggenan D A 1935 Ann. Physik. 24636

Cartithers I C 1938 Trans. Faraday Soc. 34300

Davis S S and Smith A 1972 J. Phatm. Pharmol, Sci. Comman. Suppl 24155

Dickinson W 1941 Trans. Faraday Soc. 37140

Dukhin S S 1971 in Surface and Collond Sci. (ed.) E Mategeric (New York: Wiley-Inter Science) 383

Elworthy P H and Florence A T 1969a J. Pharm. Fharmacol. 2170

Elworthy P H and Florence A T 1969b J. Pham. Pharmacol, 21708

Fradkina E M 1950 Zh. Ekss. Teor. Fiz. 20 1011

Fricke H and Curtis H J 1937 J. Phys. Chem. 41729

Growney G 1941 Trons. Faraday Soc, 37148

Franai T 1959 Kolloid. $Z h_{+} 16741$

Hanai T 1960 Kollod, Zh. 17123

Hanai $T 1961$ Kolloid. $Z h, 17757$

FIanai T, Koizumi N and Gotoh R 1962 Kolloid. Zh. 184143

Hanai T 1968 Emulsion Science (ed.) P Sherman (London: Academic Pressi p 393

Hans Mueller 1935 Colloid Sumposium Monograph 112712

Kubo $M$ and Nakamura $S 1953$ Bull, Chem. Soc. Jpn 26318

Mackor E L 1951 Rectrat. Chim. 70 663, 763

March A 1927 Ann. Pbysik. 84605

March A 1935 Trans. Faraday Soc. 31 1468

Nash R A and Hacger B E 1966 J. Pharm. Sci. 55442 
Ottewill R. H 1967 Nonionic surfactants (ed.) M J Schick (New York: Marcel Dekker Inc.) I ed, p 636 Von Plekara A 1932a Kolloid Zh 58283

Von Piekara A 1932b Kollotd Zh 59 I2

Rayleigh L. 1892 Philos. Mag. 32481

Riddick T M 1968a Controll of collotil srahility through zeta potential (New York: Zelameter Inc) 1 st ed. 27 Riddick 'T M 1968b Controf of colloid stability through zeta potential (New York: Zetameter Inc.) Ist ed. p 198 Riddick T M 1970 Am. Perfum. Commet 8536

Roborts A L 1936 Trams, Ftradoy Suc. 321705

Schott $\mathrm{H}$ and Young T W $1972 \mathrm{~J}$. Pharm. Sci. 61 183

Schwatl H P 1951 Z Nature Forsch 66121

Schwan H P 1968 Naw York Acad. Sci. 148191

Smoluchowski M V 1918 Z. Physik Chem. 93129

Weiner O 1912 Abh. Math. Phys. Kgl. Sach. Ges Wissensch, 32509 